University of Nebraska - Lincoln

DigitalCommons@University of Nebraska - Lincoln

May 2003

\title{
Magnetic hysteresis of mechanically alloyed Sm-Co nanocrystalline powders
}

\author{
J. Zhou \\ University of Nebraska - Lincoln \\ Ralph Skomski \\ University of Nebraska-Lincoln, rskomski2@unl.edu \\ David J. Sellmyer \\ University of Nebraska-Lincoln, dsellmyer@unl.edu
}

Follow this and additional works at: https://digitalcommons.unl.edu/physicssellmyer

Part of the Physics Commons

Zhou, J.; Skomski, Ralph; and Sellmyer, David J., "Magnetic hysteresis of mechanically alloyed Sm-Co nanocrystalline powders" (2003). David Sellmyer Publications. 36.

https://digitalcommons.unl.edu/physicssellmyer/36

This Article is brought to you for free and open access by the Research Papers in Physics and Astronomy at DigitalCommons@University of Nebraska - Lincoln. It has been accepted for inclusion in David Sellmyer Publications by an authorized administrator of DigitalCommons@University of Nebraska - Lincoln. 


\title{
Magnetic hysteresis of mechanically alloyed Sm-Co nanocrystalline powders
}

\author{
J. Zhou, ${ }^{\text {a) }}$ R. Skomski, and D. J. Sellmyer \\ Behlen Laboratory of Physics and Center for Materials Research and Analysis, University of Nebraska, \\ Lincoln, Nebraska 68588
}

(Presented on 12 November 2002)

\begin{abstract}
Mechanically alloyed $\mathrm{Sm}-\mathrm{Co}$ powders and $\mathrm{Sm}_{12}(\mathrm{Co}, \mathrm{Cu}, \mathrm{Ti})_{88}$ powders are investigated. X-ray diffraction patterns show that after annealing, structures of 2:7, 1:5, and 1:7 phases form. A room-temperature coercivity of $41 \mathrm{kOe}$ was obtained in $\mathrm{Sm}_{2} \mathrm{Co}_{7}$ powders. Magnetic hysteresis was investigated by the method of $\delta m$ curves. Positive value $\delta m$ curves were obtained in $\mathrm{Sm}_{2} \mathrm{Co}_{7}$ and $\mathrm{SmCo}_{5}$, while negative values were found in $\mathrm{SmCo}_{7.3}$ and $\mathrm{SmCo}_{8}$ indicating different magnetization reversal mechanisms. Nanocrystalline powders of $\mathrm{Sm}_{12}(\mathrm{Co}, \mathrm{Cu}, \mathrm{Ti})_{88}$ with a mixture of 1:5 and 2:17 phases form after long-time heat treatment. The intrinsic coercivity of the powders increases with an increasing amount of $\mathrm{Cu}$. Short annealing time produces 1:7 phase with higher crystalline anisotropy, which results in larger coercivity. (C) 2003 American Institute of Physics.
\end{abstract}

[DOI: $10.1063 / 1.1558587$ ]

\section{INTRODUCTION}

Mechanical alloying (MA) and mechanical milling (MM) have been used extensively to obtain nanocrystalline and nanocomposite magnetic materials with significant improvement of magnetic properties. ${ }^{1}$ In MA or MM Sm-Co permanent magnets, large coercivity and enhancement of remanence can be achieved through controlled grain size, fine microstructures, and large anisotropy field. Ding et al. reported a $57 \mathrm{kOe}$ coercivity in a $\mathrm{Sm}_{0.19} \mathrm{Co}_{0.81}$ MA powder. ${ }^{2}$ $\mathrm{Sm}_{2} \mathrm{Co}_{17}$ : $\mathrm{Co}$ and $\mathrm{SmCo}_{5}: \mathrm{Fe} \mathrm{MA}$ nanocomposites were reported by Chen et al. ${ }^{3}$ and Zhang et al. ${ }^{4}$ Recently, Chen et al. reported the magnetic properties of mechanically milled $\mathrm{Sm}_{2}(\mathrm{CoM})_{17}$, where M represents $\mathrm{Zr}$, Hf, Nb, V, Ti, $\mathrm{Cr}, \mathrm{Cu}$, and $\mathrm{Fe}^{5}$ It is well known that two-phase $\mathrm{Sm}-\mathrm{Co}$ 2:17-type magnets have a cellular microstructure, consisting of a 2:17 main phase surrounded by a $\mathrm{Cu}$-rich 1:5 grainboundary phase. ${ }^{6}$ A similar nanostructure is realized in $\mathrm{Sm}(\mathrm{Co}, \mathrm{Cu}, \mathrm{Ti})_{\mathrm{z}}$ two-phase magnets. ${ }^{7}$ In this article, we investigate mechanically alloyed $\mathrm{SmCo}_{z}$ and $\mathrm{Sm}(\mathrm{Co}, \mathrm{Cu}, \mathrm{Ti})_{z}$ magnets. Particular emphasis is on the magnetization reversal magnetism.

\section{SAMPLE PREPARATION AND CHARACTERIZATION}

$\mathrm{Sm}_{2} \mathrm{Co}_{7}, \mathrm{SmCo}_{5}$, and Co powders are used to prepare $\mathrm{Sm}-\mathrm{Co}$ MA powders. $\mathrm{Sm}, \mathrm{Co}, \mathrm{Cu}$, Ti elemental powders are used to obtain $\mathrm{Sm}-\mathrm{Co}-\mathrm{Cu}-\mathrm{Ti}$ powders. The starting materials are sealed in a vial together with hardenedsteel balls under $\mathrm{Ar}$ atmosphere. The compositions studied are $\mathrm{Sm}_{2} \mathrm{Co}_{7}, \mathrm{SmCo}_{5}, \mathrm{SmCo}_{7.3}, \mathrm{SmCo}_{8}$, and $\mathrm{Sm}_{12} \mathrm{Co}_{88-x-y} \mathrm{Cu}_{x} \mathrm{Ti}_{y}$ with $x=0,4,6,7,8,9$ and $y=0,3$. Mechanical alloying is done by placing the vial in a highenergy Spex 8000 mixer/mill and milling for $5 \mathrm{~h}$. Heat treatment is performed by sealing the powder in a quartz tube in an $\mathrm{Ar}$ atmosphere and then annealing in the range between 725 and $825^{\circ} \mathrm{C}$ for 5 or $30 \mathrm{~min}$. The crystal structure is

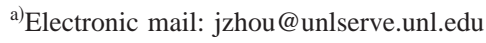

examined by x-ray diffraction with $\mathrm{Cu} K \alpha$ radiation. A superconducting quantum interference device magnetometer and a vibrating sample magnetometer with a high-temperature oven are used to measure the magnetic properties.

$\mathrm{X}$-ray diffraction (XRD) patterns show the as-milled powder is in the "X-ray" amorphous state. Sm-Co powders are heat treated at 800 and $775^{\circ} \mathrm{C}$ for $5 \mathrm{~min}$. The XRD patterns show 2:7, 1:5, 1:7, and 1:7 phases corresponding to the powder compositions of $\mathrm{Sm}_{2} \mathrm{Co}_{7}, \mathrm{SmCo}_{5}, \mathrm{SmCo}_{7.3}$, and $\mathrm{SmCo}_{8}$, respectively. $\mathrm{Sm}_{12}(\mathrm{Co}, \mathrm{Cu}, \mathrm{Ti})_{88}$ powders show mainly the $2: 17$ structure after annealing at $825^{\circ} \mathrm{C}$ for 5 or $30 \mathrm{~min}$. Figure 1 shows the development of crystallization of $\mathrm{Sm}_{12} \mathrm{Co}_{81} \mathrm{Cu}_{4} \mathrm{Ti}_{3}$ powder for different annealing times. There is a small amount of the 1:5 phase present, also. There may be a small amount of 1:7 phase, but it cannot be determined due to the overlapping of peaks. Based on the calculation from Scherrer's formula, the average grain size ranges is about $35-50 \mathrm{~nm}$ and does not increase much with further annealing. XRD patterns for other $\mathrm{Sm}-\mathrm{Co}-\mathrm{Cu}-\mathrm{Ti}$ compositions show similar results.

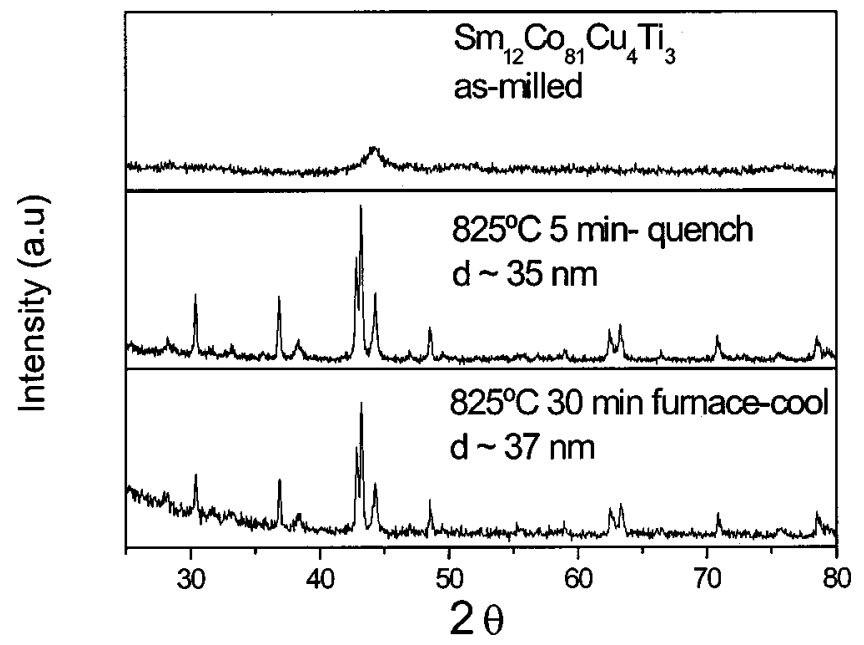

FIG. 1. X-ray diffraction patterns of mechanical alloyed $\mathrm{Sm}_{12} \mathrm{Co}_{81} \mathrm{Cu}_{4} \mathrm{Ti}_{3}$. 


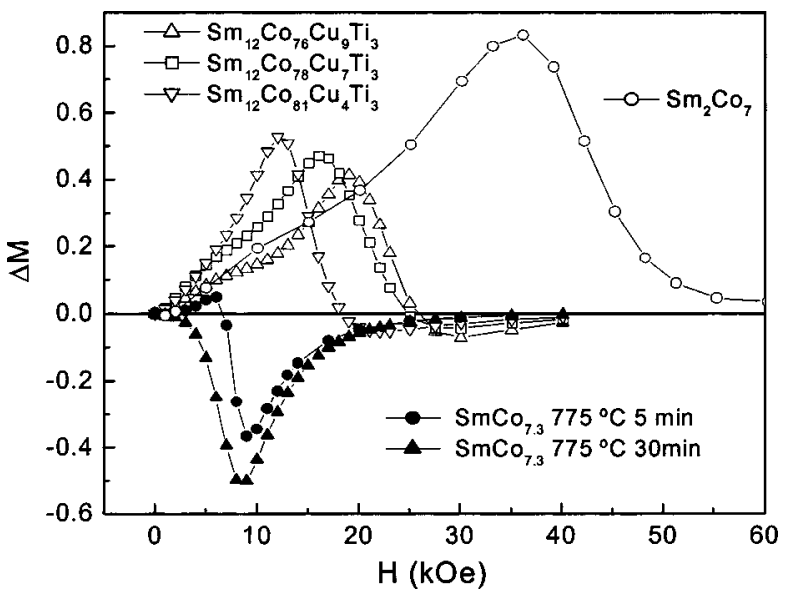

FIG. 2. $\Delta \mathrm{m}$ curves of $\mathrm{Sm}_{2} \mathrm{Co}_{7}, \mathrm{SmCo}_{7.3}$, and $\mathrm{Sm}-\mathrm{Co}-\mathrm{Cu}-\mathrm{Ti}$.

\section{MAGNETIC PROPERTIES}

Magnetic hysteresis measurements at room temperature show single-phase behavior for all the samples. For $\mathrm{Sm}_{2} \mathrm{Co}_{7}$, $\mathrm{SmCo}_{5}, \mathrm{SmCo}_{7.3}$, and $\mathrm{SmCo}_{8}$ alloy powders, the coercivities binary are $29,8,41$, and $6 \mathrm{kOe}$, respectively. This is due to the smaller anisotropy constants in Co-rich alloys $\left[K_{1}\right.$ $=17.2 \mathrm{MJ} \mathrm{m}^{-3}$ for $\mathrm{SmCo}_{5}$ and $3.3 \mathrm{MJ} \mathrm{m}^{-3}$ for $\mathrm{Sm}_{2} \mathrm{Co}_{17}$ (Ref. 8)]. $\Delta m$ curves of these samples are measured to investigate the magnetic hysteresis mechanism. $\mathrm{Sm}_{2} \mathrm{Co}_{7}$ and $\mathrm{SmCo}_{5}$ samples show positive $\Delta m$ value while $\mathrm{SmCo}_{7.3}$ (shown in Fig. 2) and $\mathrm{SmCo}_{8}$ show negative value. We also observed similar $\Delta m$ curves in Sm-Co thin films. ${ }^{9}$ The explanation for this difference will be discussed and compared to $\mathrm{Sm}-\mathrm{Co}-\mathrm{Cu}-\mathrm{Ti}$ powders later.

Table I shows the magnetic properties of $\mathrm{Sm}-\mathrm{Co}-$ $\mathrm{Cu}-\mathrm{Ti}$ powders. It can be seen that for binary $\mathrm{Sm}_{12} \mathrm{Co}_{88}, H_{c}$ is as low as $5.6 \mathrm{kOe}$. The remanence ratio $\left(M_{r} / M_{s}\right)$ is close to 0.5 , the ratio expected for randomly oriented uniaxialanisotropy particles. The coercivity and remanence ratio are increased by the substitution of $\mathrm{Ti}$ or $\mathrm{Cu}$ for $\mathrm{Co}$. In sintered $\mathrm{Sm}-\mathrm{Co}$ 2:17-type magnets, $\mathrm{Cu}$ is introduced to form the precipitated $\mathrm{Cu}$-rich grain boundary that provides pinning centers for domain-wall motion. ${ }^{7,10}$ According to Chen et al., ${ }^{5}$ in powder form $\mathrm{Cu}$ helps the formation of 1:5 phase and $\mathrm{Zr}$ goes to $2: 17$ phase. 1:5 and 2:17 grains are uniformly distributed in the powder particles. Our samples containing $\mathrm{Ti}$ likely have similar structures. We know that Ti usually takes

TABLE I. Magnetic properties of $\mathrm{Sm}-\mathrm{Co}-\mathrm{Cu}-\mathrm{Ti}$ powders.

\begin{tabular}{lcccccc}
\hline \hline & \multicolumn{3}{c}{$825^{\circ} \mathrm{C}, 30 \mathrm{~min}$} & & \multicolumn{2}{c}{$825^{\circ} \mathrm{C}, 5 \mathrm{~min}$} \\
\cline { 2 - 4 } \cline { 6 - 7 } & $\begin{array}{c}H_{c} \\
(\mathrm{kOe})\end{array}$ & $\begin{array}{c}M_{r} \\
(\mathrm{emu} / \mathrm{g})\end{array}$ & $\begin{array}{c}M_{s} \\
(\mathrm{emu} / \mathrm{g})\end{array}$ & & $H_{c}$ at $27{ }^{\circ} \mathrm{C}$ & $H_{c}$ at $400{ }^{\circ} \mathrm{C}$ \\
\hline $\mathrm{Sm}_{12} \mathrm{Co}_{88}$ & 5.7 & 53 & 112 & & 1.8 \\
$\mathrm{Sm}_{12} \mathrm{Co}_{82} \mathrm{Cu}_{6}$ & 9.7 & 50 & 101 & & & 2.0 \\
$\mathrm{Sm}_{12} \mathrm{Co}_{85} \mathrm{Ti}_{3}$ & 12.7 & 56 & 97 & & & 3.8 \\
$\mathrm{Sm}_{12} \mathrm{Co}_{81} \mathrm{Cu}_{4} \mathrm{Ti}_{3}$ & 12.6 & 49 & 80 & & 15.2 & 3.2 \\
$\mathrm{Sm}_{12} \mathrm{Co}_{79} \mathrm{Cu}_{6} \mathrm{Ti}_{3}$ & 12.0 & 49 & 81 & & & 2.6 \\
$\mathrm{Sm}_{12} \mathrm{Co}_{78} \mathrm{Cu}_{7} \mathrm{Ti}_{3}$ & 16.2 & 48 & 77 & & 19.7 & 3.3 \\
$\mathrm{Sm}_{12} \mathrm{Co}_{77} \mathrm{Cu}_{8} \mathrm{Ti}_{3}$ & 15.8 & 48 & 79 & & 17.2 & 3.5 \\
$\mathrm{Sm}_{12} \mathrm{Co}_{76} \mathrm{Cu}_{9} \mathrm{Ti}_{3}$ & 17.1 & 45 & 73 & & 22.2 & 4.0 \\
\hline \hline
\end{tabular}

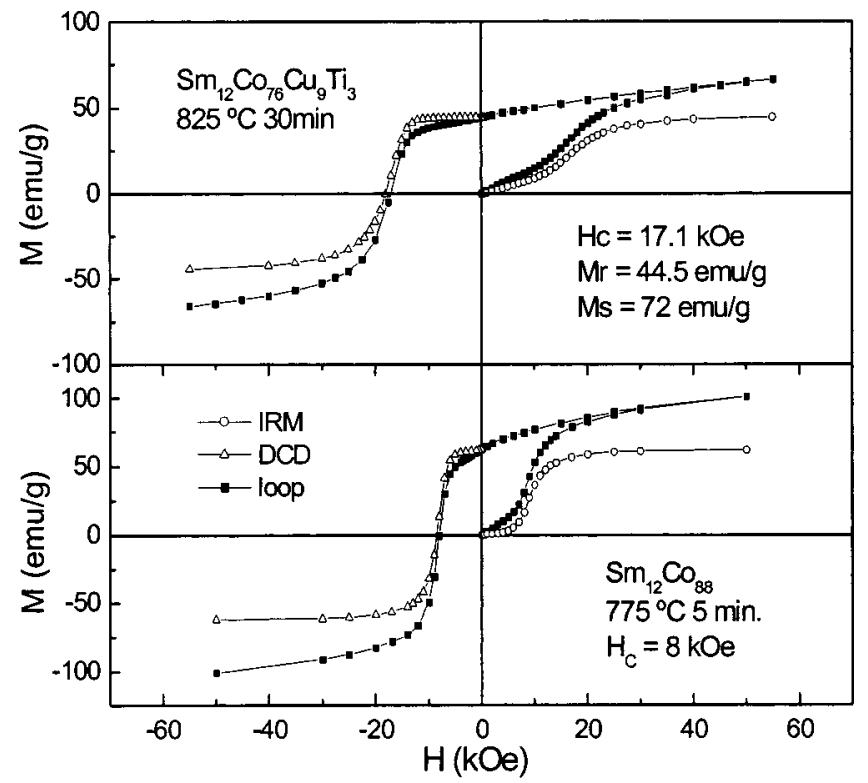

FIG. 3. Initial IRM, and DCD curves of $\mathrm{Sm}_{12} \mathrm{Co}_{88}$ and $\mathrm{Sm}_{12} \mathrm{Co}_{76} \mathrm{Cu}_{9} \mathrm{Ti}_{3}$.

the Co dumbbell sites, which will increase the anisotropy of the SmCo alloys, ${ }^{11}$ and Cu-rich phases, most likely 1:5, provide pinning centers to impede domain-wall motion, which increases the coercive force.

All the samples heat treated at $825^{\circ} \mathrm{C}$ for $5 \mathrm{~min}$ show larger $H_{c}$ than those annealed for $30 \mathrm{~min}$ with the same compositions. This can be understood as a longer heat treatment produces larger crystallite size, as well as decomposes the 1:7 phase into $1: 5$ and $2: 17$ phases. The relatively low anisotropy of the $2: 17$ phase makes the coercivity of the powder smaller.

The high-temperature coercivity of the powder samples shows that $H_{c}$ decreases as the temperature increases. This is mainly due to the change of anisotropy with the changing temperature. It can be seen that the high-temperature coercivity does not increase with additional $\mathrm{Cu}$ in $\mathrm{Sm}_{12} \mathrm{Co}_{85} \mathrm{Ti}_{3}$. That is because $\mathrm{Cu}$ decreases both Curie temperature and the high-temperature anisotropy of the $\mathrm{SmCo}_{5}$ phase.

\section{MAGNETIZATION REVERSAL MECHANISM}

To understand the coercivity mechanism of the Sm-Cobased mechanical alloys we investigated the remanentmagnetization $\Delta m$ behavior. $\Delta m$ is defined as $\Delta m=m_{d}$ $-\left(1-2 m_{r}\right)$ where $m_{d}$ is the reduced magnetization from DCD measurement and $m_{r}$ is the reduced remanence from IRM measurement. According to Wohlfarth, the deviation is zero for non-interacting uniaxial single-domain particles. ${ }^{12}$ It is commonly accepted that a negative $\delta m$ value indicates the dipole interactions ${ }^{13}$ and a positive value indicates ferromagnetic exchange interactions between isolated single-domain particles. Several papers discussed the magnetization behavior in permanent-magnet materials, ${ }^{14,15}$ including the influence of the pinning mechanism on $\Delta m$. Skomski gave an example that domain-wall pinning also can generate a positive $\Delta m .{ }^{16}$ Vajda et al. also pointed out that the demagnetization state will influence the $\Delta m$ behavior. ${ }^{17}$ Other researchers have explained the positive value of $\Delta m$ as evidence of 

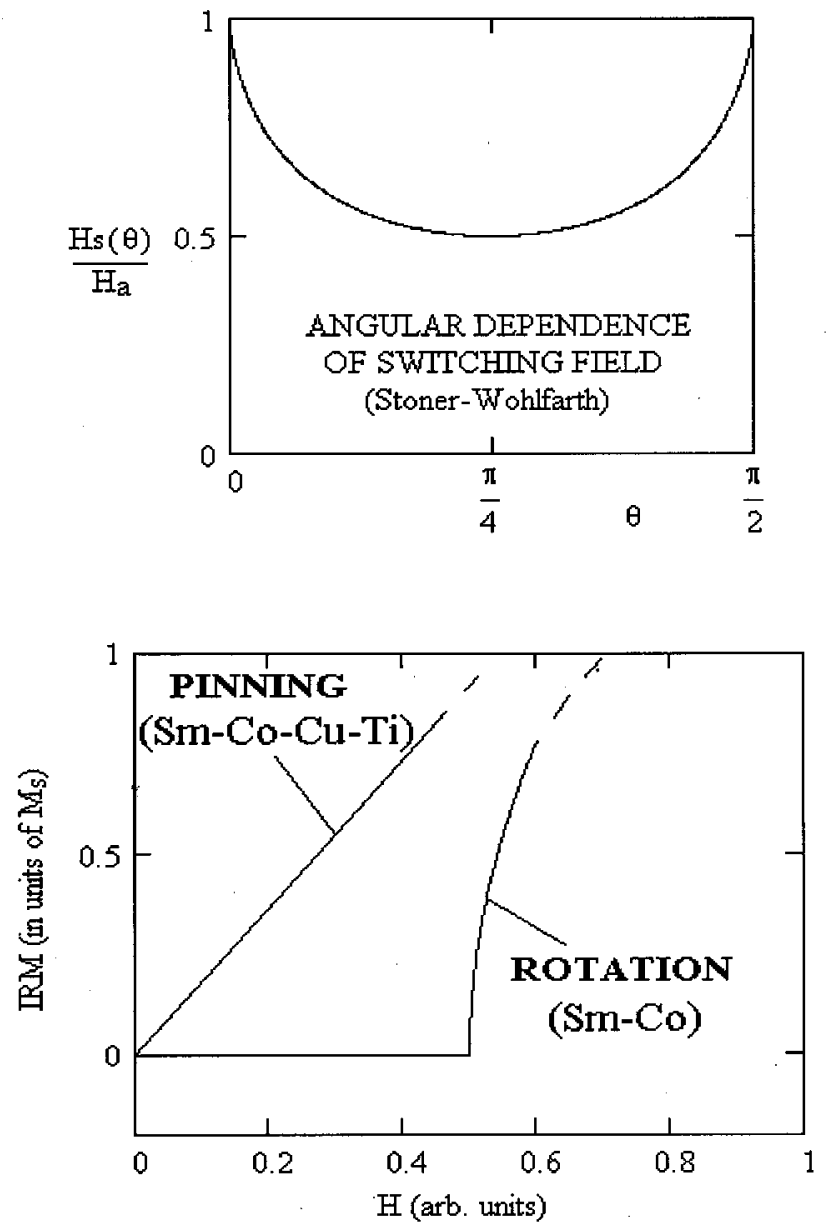

FIG. 4. Switching fields and IRM curves (schematic).

exchange interactions in nanocomposite between the hard and soft magnetic materials. ${ }^{18,19}$ In this work, we attribute the $\Delta m$ behavior to the basic mechanisms of coercivity: wall pinning or incoherent rotation.

In our experiment, the initial samples are in thermally demagnetized state. Figure 3 shows the initial curve, IRM and DCD curves for mechanically alloyed $\mathrm{Sm}_{12} \mathrm{Co}_{88}$ and $\mathrm{Sm}_{12} \mathrm{Co}_{76} \mathrm{Cu}_{9} \mathrm{Ti}_{3}$ powders. Other samples show similar behaviors. It can be seen that in Fig. 3(a), the remanence from the IRM curve gradually increases with the increasing field and the difference between IRM and initial curves is small before the field reaches the coercive field. This indicates that the magnetization process is mainly controlled by domainwall pinning. During the process, the domain walls move overcoming the impedance from the pinning centers that are $\mathrm{Cu}$ - and Ti-containing phases. When the field is removed, the remanence is retained because the domain walls are pinned. The initial curve is also consistent with the typical curve for the $\mathrm{Sm}-\mathrm{Co}$ 2:17 magnet with a distribution of pinning centers. ${ }^{8} \mathrm{Sm}_{2} \mathrm{Co}_{7}$ and $\mathrm{SmCo}_{5}$ showing positive $\Delta m$ value in Fig. 2 have similar IRM and DCD behaviors, but the coercivity is controlled by nucleation, not pinning. The strong exchange interactions tend to align the magnetization of grains. So during the magnetization process, when the field is removed, remanence is retained as a result of intergrain exchange interactions. Thus, a positive $\Delta m$ curve is obtained.
In Fig. 3(b), for $\mathrm{Sm}_{12} \mathrm{Co}_{88}$ powders, the IRM remanence remains almost unchanged at low field, while the initial curve at the corresponding field gives a large magnetization. This is because of the coercivity mechanism in these powders is mainly incoherent rotation. According to Stoner and Wohlfarth's model, ${ }^{8,20}$ the switching field $H_{s}$, at which the change in the equilibrium direction of magnetization becomes discontinuous, is given by ${ }^{8}$

$$
H_{s}=\frac{2 K_{1}}{\mu_{0} M_{s}} \frac{1}{\left(\cos ^{2 / 3} \Theta+\sin ^{2 / 3} \Theta\right)^{3 / 2}} .
$$

Figure 4(a) shows the angular dependence of the switching field in the model. Considering that the $\mathrm{Sm}_{12} \mathrm{Co}_{88}$ powder is an ensemble of weakly interacting fine particles with random orientation, ideally a small reverse field $H<0.5 H_{A}$ (anisotropy field) yields a reversible rotation of the magnetization direction, but in large reverse fields the magnetization is irreversible. ${ }^{8}$ Figure 4 shows the theoretical IRM curves for the two different magnetization reversal mechanisms.

Figure 3 shows the $\Delta m$ curve of $\mathrm{Sm}-\mathrm{Co}-\mathrm{Cu}-\mathrm{Ti}$ and $\mathrm{Sm}-\mathrm{Co}$ powders. Because of the different IRM behaviors, $\Delta m$ yields different values. In this case, negative $\Delta m$ for Co-rich $\mathrm{Sm}-\mathrm{Co}$ is due to the incoherent rotation and positive $\Delta m$ for $\mathrm{Sm}-\mathrm{Co}-\mathrm{Cu}-\mathrm{Ti}$ comes from the domain-wall pinning, while positive $\Delta m$ for $\mathrm{Sm}_{2} \mathrm{Co}_{7}$ and $\mathrm{SmCo}_{5}$ (not shown, similar to that of $\mathrm{Sm}-\mathrm{Co}-\mathrm{Cu}-\mathrm{Ti}$ ) is due to strong exchange interaction.

This work is supported by DOE, AFOSR, DARPA/ARO, and CMRA.

${ }^{1}$ P. G. McCormick, W. F. Miao, P. A. I. Smith, J. Ding, and R. Street, J. Appl. Phys. 83, 6256 (1998), and references therein.

${ }^{2}$ J. Ding, P. G. McCormick, and R. Street, J. Alloys Compd. 191, 197 (1993).

${ }^{3}$ S. K. Chen, J. L. Tsai, and T. S. Chin, J. Appl. Phys. 79, 5964 (1996).

${ }^{4}$ J. Zhang, S. Y. Zhang, H. W. Zhang, and B. G. Shen, J. Appl. Phys. 89, 5601 (2001)

${ }^{5}$ Z. Chen, X. Meng-Burany, H. Okumura, and G. C. Hadjipanayis, J. Appl. Phys. 87, 3409 (2000).

${ }^{6}$ K. Kumar, J. Appl. Phys. 63, R13 (1988).

${ }^{7}$ J. Zhou, R. Skomski, C. Chen, G. C. Hadjipanayis, and D. J. Sellmyer, Appl. Phys. Lett. 77, 1514 (2000).

${ }^{8}$ R. Skomski and J. M. D. Coey, Permanent Magnetism (Institute of Physics, Bristol, 1999).

${ }^{9}$ D. J. Sellmyer, J. Zhou, Y. Liu, and R. Skomski, Proceedings of the 17th Work Shop on Rare-Earth Magnets and Their Applications, Delaware (2002).

${ }^{10}$ J. Zhou, R. Skomski, and D. J. Sellmyer, IEEE Trans. Magn. 37, 2518 (2001).

${ }^{11}$ J. Zhou, I. A. Al-Omari, J. P. Liu, and D. J. Sellmyer, J. Appl. Phys. 87, 5299 (2000).

${ }^{12}$ E. P. Wohlfarth, J. Appl. Phys. 29, 595 (1954).

${ }^{13}$ J. Garcia-Otero, M. Porto, and J. Rivas, J. Appl. Phys. 87, 7376 (2000).

${ }^{14}$ P. Gaunt, G. Hadjipanayis, and D. Ng, J. Magn. Magn. Mater. 54-57, 841 (1986).

${ }^{15}$ F. E. Pinkerton and D. J. Van Wingerden, J. Appl. Phys. 60, 3685 (1986).

${ }^{16}$ R. Skomski and D. J. Sellmyer, J. Appl. Phys. 89, 7263 (2001).

${ }^{17}$ F. Vajda, E. Della Torre, and R. D. McMichael, J. Appl. Phys. 75, 5689 (1994); R. D. McMichael, F. Vajda, and E. Della Torre, ibid. 75, 5692 (1994).

${ }^{18}$ W. C. Chang, S. H. Wu, B. M. Ma, C. O. Bounds, and S. Y. Yao, J. Appl. Phys. 83, 2147 (1998).

${ }^{19}$ Z. Chen, H. Okumura, G. C. Hadjipanayis, and Q. Chen, J. Appl. Phys. 89, 2299 (2001)

${ }^{20}$ E. C. Stoner and E. P. Wohlfarth, Philos. Trans. R. Soc. London, Ser. A 240, 599 (1948); IEEE Trans. Magn. 27, 3475 (1991). 